\title{
Towards a Sustainable Circular Economy Remarks on plastics and wood-waste sector
}

\section{Markus WILL \\ University of Applied Sciences Zittau/Görlitz, Germany}

\begin{abstract}
:
Aim: As the traditional approach towards entering a path of sustainable development based on a "efficiency, consistency, sufficiency approach" is questionable, This article discusses opportunities and challenges for the circular economy to become a "last chance" for the current capitalistic and market based system to become more sustainable.
\end{abstract}

Design / Research methods: Two case studies of material (waste) streams of plastics and wood-waste are presented in order to identify challenges in the development and functioning of the circular economy.

Conclusions / findings: While the circular economy can deal with threats to sustainability embraced in an efficiency and sufficiency approach, it refers to a technology-driven consistency approach, not questioning the consumption and production patterns in the capitalist economy, and the functioning of the market economy as such.

Key words: Circular economy, recycling, sustainability

JEL: Q53, Q56

Correspondence address: Markus Will, University of Applied Sciences Zittau/Görlitz, Zittau, Germany. E-mail: M.Will@hszg.de.

Received: 11.12.2019, Revised: 24.12.2019, Accepted: 25.12.2019

doi: http://dx.10.29015/cerem.862 


\section{Justifying the circular economy as sustainability strategy}

Given the assumption is correct, that in modern economies production and consumption patterns systematically lead to an overexploitation of natural resources and social cost of this overuse are ignored (i.e. externalized), the unsettled question is how to deal with it. Often three strategies are suggested to achieve 'true' sustainability (Dyllick, Muff 2016), i.e. sufficiency, efficiency and consistency (Jörissen et al. 1999; Harborth 1991; Huber 1995).

Figure 1. The three sustainability strategies: efficiency, consistency, sufficiency

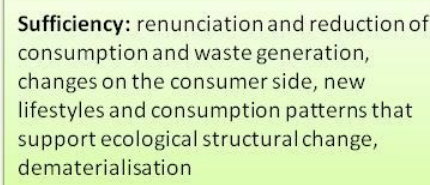

\section{Sustainability}

Efficiency: performance-orientation, Input/Output-relation („,doing more with less"), company perspective, changes in the production process through technical and organizational innovations
Consistency: embeddedness, compatibility and composition of materials, embedding in ecosystems, adapted material flows, low-risk technologies

Source: based on Jörissen et al. (1999); Harborth (1991); Huber (1995).

While the efficiency and the consistency approach rely on technological progress, sufficiency is not a technological and incentive-based approach. Indeed it requires personal life-style changes, a post-materialistic attitude, the ability to restrain from superfluous consumption, an "inner climate change" (Sieben 2007) 
and so on. It requires consumers to start thinking about externalized cost and considering ecological limits, before buying or using items. Hence, sufficiency is not an easy strategy for most people especially in western societies, although it is seen as beneficial for humans in terms of individual wellbeing (Paech 2012; MüllerChrist 2009; Schumacher 1973).

Efficiency is often coined as "doing more with less" (Fussler 1996), referring to the imperative not to waste any (natural) resources when producing a certain output (as a service or product). The efficiency approach can be linked to conventional business calculi and seems least controversial strategy. Often the efficiency approach it is related to technical improvements on the energy demand side. Except of Saudi Arabi and Brazil, all other G20 countries have reduced their energy intensity from 2000 to 2014 (IEA 2017; Brüggemann 2018). Germany for instance reduced its primary energy intensity by nearly 25\% between 2000 and 2017. However, the absolute primary energy consumption decreased by a modest $6 \%$ only. This means that primary energy savings have been offset by economic growth, an effect which known as the rebound effect (Brookes 1990; Saunders 1992; Sorrell et al. 2009).

Another more technical approach to sustainability is consistency, meaning that material and production systems and their energy and material flows should be integrated into natural cycles. Examples for consistency approaches are the cradleto-cradle concept, industrial ecology and, of course, the circular economy. The circular economy refers to a socio-economic system that aims at using materials and commodities as long and as efficiently as possible in order to eliminate waste. In a circular economy products, equipment and infrastructure are kept in use as long as possible, hence the productivity of resource use should be improved. The concept of the circular economy refers to a number of core principles, often coined through different 'R-frameworks' (Kirchherr et al. 2017). A more recent framework is the 9R framework developed by Potting et al. (2017), which relies on improving the application of materials, expansion of product lifetime and a generally smarter product manufacturing and use (see Table 1). 
Table 1. 9R Framework

\begin{tabular}{|c|c|c|c|}
\hline \multirow{10}{*}{ 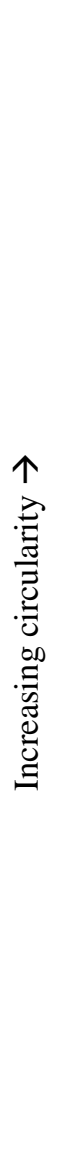 } & \multirow{3}{*}{$\begin{array}{l}\text { Smarter } \\
\text { products use } \\
\text { and } \\
\text { manufacture }\end{array}$} & R0 Refuse & $\begin{array}{l}\text { Making products redundant by abandoning its } \\
\text { function or by offering same function with } \\
\text { radically different products }\end{array}$ \\
\hline & & R1 Rethink & $\begin{array}{l}\text { More intensive product use, e.g. by sharing } \\
\text { products }\end{array}$ \\
\hline & & R2 Reduce & $\begin{array}{l}\text { Increased energy and material efficiency in } \\
\text { product manufacturing }\end{array}$ \\
\hline & \multirow{5}{*}{$\begin{array}{l}\text { Extend } \\
\text { lifespan of } \\
\text { product and } \\
\text { its parts }\end{array}$} & R3 Reuse & $\begin{array}{l}\text { Reuse of discarded products, with good } \\
\text { conditions by other consumers }\end{array}$ \\
\hline & & R4 Repair & Repair and maintenance of defective products \\
\hline & & R5 Refurbish & $\begin{array}{l}\text { Restoration/refurbishment of old products, } \\
\text { incl. updating }\end{array}$ \\
\hline & & $\begin{array}{l}\text { R6 } \\
\text { Remanufacture }\end{array}$ & $\begin{array}{l}\text { Use of parts of discarded products in a new } \\
\text { product with same function }\end{array}$ \\
\hline & & R7 Repurpose & $\begin{array}{l}\text { Use of discarded products or parts in a new } \\
\text { product with a different function }\end{array}$ \\
\hline & \multirow{2}{*}{$\begin{array}{l}\text { Useful } \\
\text { application } \\
\text { of materials }\end{array}$} & R8 Recycle & $\begin{array}{l}\text { Recycling of materials with high grade or low } \\
\text { grade quality }\end{array}$ \\
\hline & & R9 Recover & Incineration of material and energy recovery \\
\hline
\end{tabular}

Source: Potting et al. (2017).

Another core principle is "waste-equals-food", meaning that by-products, recovered products and recycled materials refer as inputs for another industrial process (i.e. technical nutrients). Organic and digestible, biodegradable or bio-based materials should be reintroduced through non-toxic or restorative loops. All these principles should be employed in order to close material loops and to foster to overcoming the traditional "take-make-waste" linear economy. In such as system, materials are no longer consumables, but have to cascade through different applications. In the end-of-life phase, valuable feedstock materials will be reintroduced in the biosphere for composting or into the technosphere for recycling 
and/or upcycling. The resulting restorative industrial system, is often depicted with the "butterfly diagram" (see Figure 2).

\section{Figure 1. The Butterfly-diagram of the circular economy}

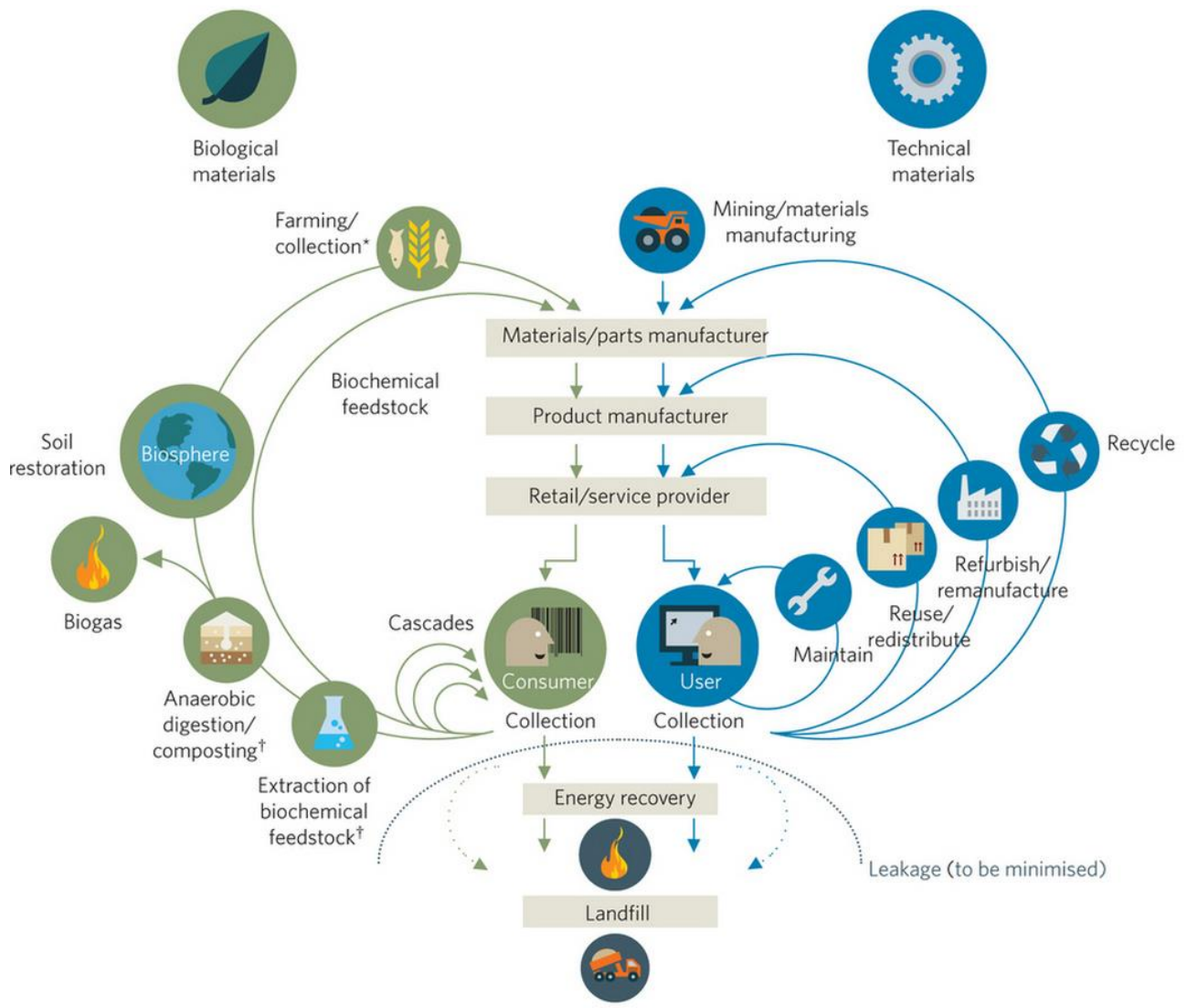

Source: EMF (2013).

The proponents of the circular economy intuitively assume that circularity would appear to be more sustainable than the current linear system. Indeed, the circular economy is an approach that allows achieving a more sustainable society without radical changes in consumption patterns. It can be achieved within the predominant economic paradigm and without loss of revenues and unreasonable extra cost for manufactures. The idea of the circular economy would allow producers to keep going with a 'the-same-but-circular-business' while consumers can keep enjoying an overwhelming variety of products and services. And precisely 
because everything can go on, and a transformation of capitalism does not seem necessary, as it is sometimes demanded in the context of the left- and rightwing capitalism-critical debate on degrowth (D'Alisa et al. 2014), the concept is so wonderfully adaptable. It is evident nowadays, that the concept has gained importance on the political agenda (i.e. the European Circular Economy Package from 2015, the Chinese Circular Economy Promotion Law from 2009, the German Closed Substance Cycle and Waste Management Act from 1996 (Su et al. 2013), and the Japan's "Basic Law for Establishing a Recycling-Based Society" from 2002 (METI 2004), as well as in industry, which seems to be increasingly aware of the concept (EMF 2013b; Lieder, Rashid 2016; Brennan et al. 2015; Geissdoerfer et al. 2017). In the following sections two case studies on the plastics and waste-wood sector will be presented to provide insights into the recent state and challenges related to the implementation of a circular economy. From this case studies the conclusion can be drawn that although the circular economy obviously would allow for continuing a capitalistic economic model, but still quite a few challenges have to be tackled.

\section{The Circular Economy is not here yet}

To date, the CE is more of a vision than a concept that has already been implemented and brought to life. Apart from a few material flows (e.g. paper/cardboard, tinplate, aluminum and steel, glass and selected plastics such as PET), the recycling rates in the European countries differ considerably, especially with regard to material recycling, i.e. real recycling as opposed to waste incineration. There are still a number of technical and political hurdles to overcome in order to establish the $\mathrm{CE}$ and support a change from a linear economy to a circular model. In this section some problems will be highlighted.

\subsection{Plastic wastes and recycling - current state}

The current human age is coined as 'plasticene' (Ten Brink et al. 2018), referring to the vast amounts of plastics being produced, used and discharged. The 
term is also a suitable metaphor for the diversity of synthetic and semi-synthetic organic-materials and its importance in many domains in both industry and consumer daily life, but also for the phenomenon of plastic waste as a geological indicator (Zalasiewicz et al. 2016).

Plastics of different kinds (see Table 2) are produced in large quantities (see Figure 3), i.e. 8,300 million metric tons (Mt) from 1950 till 2015 (Geyer et al. 2017), for a broad spectrum of final products that are utilized in in different industrial applications such as lightweight materials, building and construction materials, packaging, energy electronics, and health.

\section{Table 2. Selected examples of plastics and their applications and potential} recyclability

\begin{tabular}{|l|l|l|}
\hline Type of Plastic & Example Application & Recyclability \\
\hline $\begin{array}{l}\text { Polyethylene } \\
\text { Terephthalate (PET) }\end{array}$ & $\begin{array}{l}\text { water bottles, medicine jars, combs, bean } \\
\text { bags, ropes, carpet }\end{array}$ & Easy to recycle \\
\hline $\begin{array}{l}\text { High-Density } \\
\text { Polyethylene (HDPE) }\end{array}$ & $\begin{array}{l}\text { milk jugs, juice container, grocery bags, } \\
\text { trash bags, shampoo and conditioner } \\
\text { bottles, toys }\end{array}$ & Easy to recycle \\
\hline Polypropylene (PP) & $\begin{array}{l}\text { plastic diapers, kitchenware, yogurt } \\
\text { container, bottle caps, disposable cups } \\
\text { and plates }\end{array}$ & Easy to recycle \\
\hline $\begin{array}{l}\text { Low-Density } \\
\text { Polyethylene (LDPE) }\end{array}$ & $\begin{array}{l}\text { Sandwich bags, frozen food bags, } \\
\text { Flexible container lids }\end{array}$ & $\begin{array}{l}\text { Easy to recycle } \\
\text { (most recycled } \\
\text { type of plastic) }\end{array}$ \\
\hline $\begin{array}{l}\text { Polyvinyl Chloride } \\
\text { (PVC) }\end{array}$ & $\begin{array}{l}\text { grocery bags, tiles, cling films, shoes, } \\
\text { window frames, sewage pipes }\end{array}$ & Difficult to recycle \\
\hline $\begin{array}{l}\text { Polystyrene or } \\
\text { Styrofoam (PS/EPS) }\end{array}$ & $\begin{array}{l}\text { Plastic food boxes, Disposable coffee } \\
\text { cups, plastic cutlery }\end{array}$ & Difficult to recycle \\
\hline Miscellaneous Plastics & $\begin{array}{l}\text { Plastic CD's \&DVD's, Baby bottle, } \\
\text { Eyeglasses }\end{array}$ & Difficult to recycle \\
\hline
\end{tabular}

Source: Leal Filho et al. (2019).

${ }^{1}$ Polycarbonate, polyctide, acrylic, acrylonitrile butadiene, styrene, fiberglass, and nylon. 
Figure 2. Annual global polymer resin production 1950 - 2015, in million metric tons

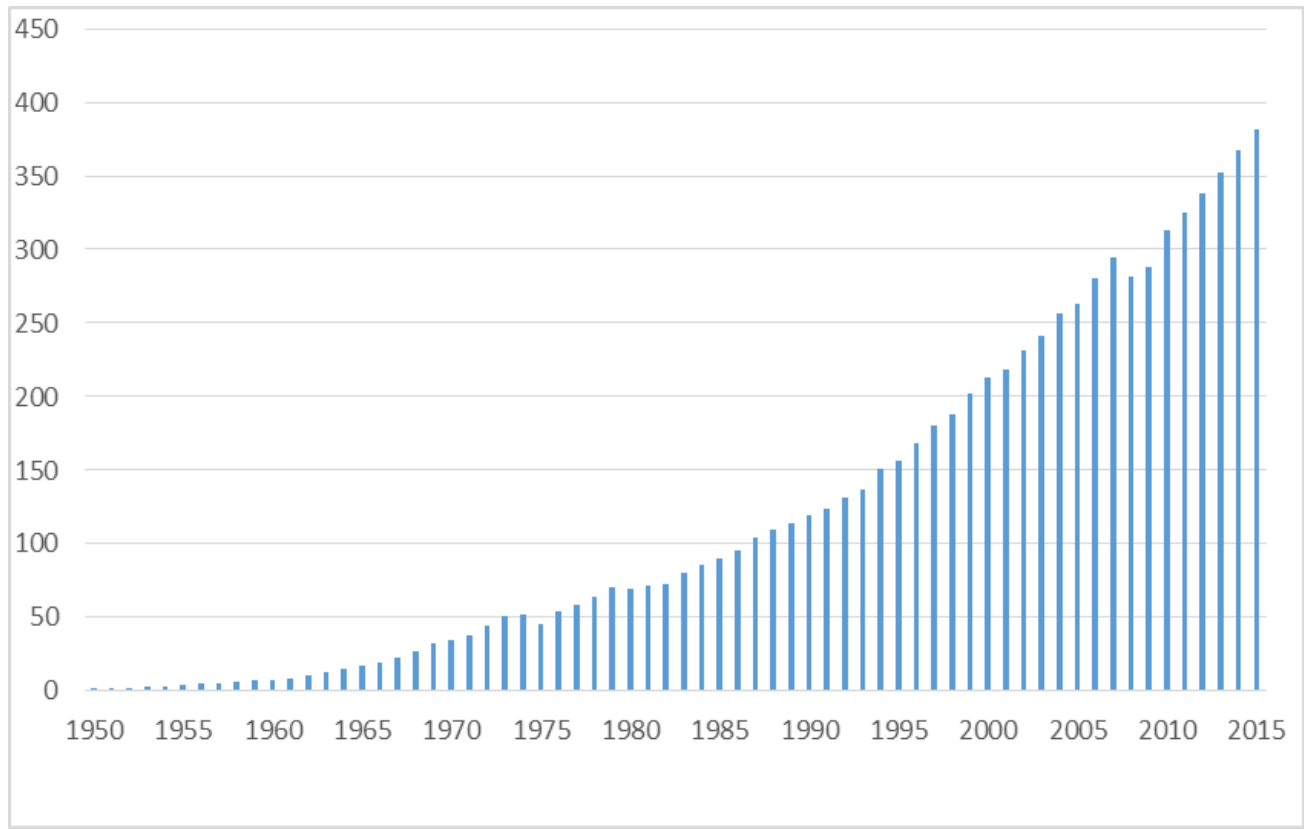

Data source: Geyer et al. (2017).

Plastics have several benefits: they are lightweight, strong, durable and mostly low cost, which makes them a valuable and widespread material. Their use and production rate is on a global scale likely to increase. When dealing with plastics from an environmental sustainability point of view, i.e. focusing on waste issues and toxic additives, it shall be taken into account, that plastics also have several benefits. For instance, with lightweight materials in vehicles or as high-performance insulation materials, the energy and fuel consumptions can be reduced which leads to reduced GHG emissions as well (PlasticsEurope 2018). As plastics are durable, they are particularly effective as flexible packaging material and are used to protect food and preserve the amount of food waste mainly by prolonged shelf-time in stores (Robertson 2009, 2016).

However, waste from plastics may cause adverse effects to human health and the environment. Apart from few examples of so-called bio-plastics with a minor market share of about $2 \%$ (nova institute 2019), plastics are usually derived from 
fossil-hydrocarbons and are non-biodegradable. In case of insufficient waste management, large quantities of plastic waste end-up in incinerators, landfills or in the environment (see Figure 4; Jambeck et al. 2015; Geyer et al. 2017)

\section{Figure 3. Fate of plastic waste}

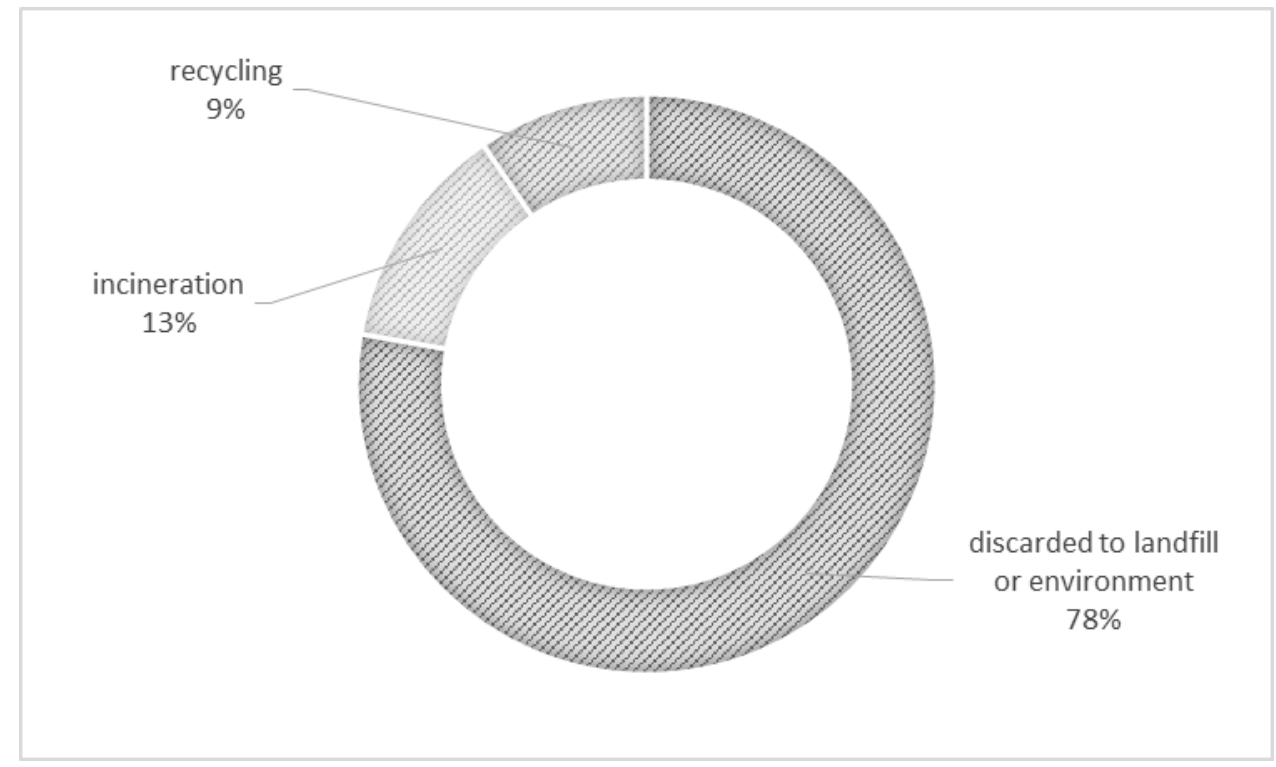

Data source: Geyer et al. (2017).

While on a global scale waste management systems are not fully implemented or efficiently working (Jambeck et al. 2015), the current situation in Europe is significantly better. According to an industry-led study, more plastics waste has been recycled than landfilled ${ }^{2}$. Of the $28 \mathrm{~m} \mathrm{t}, 42.6 \%$ were recovered through wasteto-energy, $32.5 \%$ recycled and $24.9 \%$ landfilled (see Figure 5).

\footnotetext{
${ }^{2}$ https://www.plasteurope.com/news/PLASTICS_RECYCLING_EUROPE_t238815/ 26.11.2019].
} 
Figure 4. Plastics post-consumer waste treatment in the European Union (EU28) 2018, by type

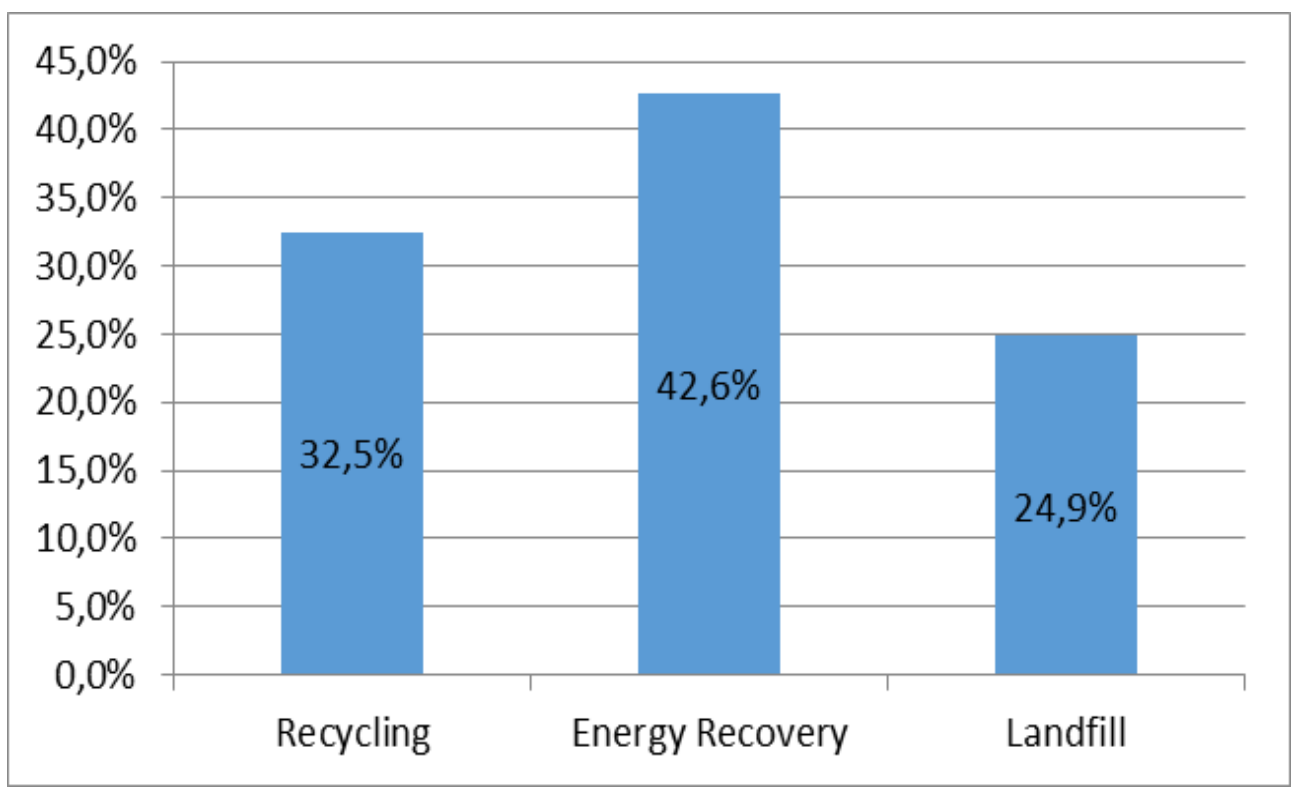

Waste incineration and integrated utilization of heat and conversion to electricity is dominating over mechanical and feedstock recycling. Feedstock recycling (or chemical recycling), such as pyrolysis or gasification, is related to a modification of the chemical structures, i.e. a break-down of polymers to produce synthetic gas (syngas) or depolymerisation into monomers. Chemical recycling is a complementary approach to minimize landfilling or to treat plastics that cannot be (sustainably) recycled my mechanical processes (for instance laminated or composite plastics, low quality or contaminated plastic streams). Feedstock recycling has so far hardly played a relevant role in terms of quantity. Most processes are also not yet suitable for industrial use. Nevertheless, there are promising approaches, especially for composite plastic packaging materials. For instance ${ }^{3}$ :

\footnotetext{
${ }^{3}$ https://packaging-journal.de/chemisches-bioenzymatisches-kunststoffrecycling/ [24.11.2019].
} 
- The Swiss company gr3n applies microwave radiation to recycle PET waste, which is broken down into ethylene glycol and terephthalic acid to be used a basic chemical. The company gr3n is a central player within the EU funded H2020 DEMETO consortium, together with industry partners such as H\&M and Coca Cola.

- ChemCyclingTM project is carried out by a consortium led by BASF and aims at the processing of difficult to recycle mixed plastic waste (i.e. multilayer packaging and composite plastics) into purified pyrolysis oil, which can be further broken down into enthylene and propylene in a steam cracker at $850^{\circ} \mathrm{C}$. First prototypes for products, such as the insulating packaging material Styropor ${ }^{\circledR}$ Ccycled $^{\mathrm{TM}}$ by Storopack and polyamide and polyethylene packaging films for mozzarella cheese produced by Südpack are available.

- There is a bioenzymatic process for plastics recycling developed by the French company Carbios. PET and other polyesters, as well as multilayer materials and functional sportswear is are broken down into their basic components. Enzymatic processes are running at significantly lower temperatures of about $65^{\circ} \mathrm{C}$. Residuals include only water non-treatable materials such as aluminium or paper.

Mechanical recycling or material recovery, representing 99\% of recycled quantities ${ }^{4}$, refers to processing waste plastics into a secondary raw material or a product, without significant changes in the chemical characteristics. In general, all kinds of pure thermoplastics can by mechanically recycling without major quality losses. Mechanical plastic recycling involves different processes such as collecting, sorting and shredding, washing, melting and pelletizing. Obviously plastic waste processing is rather specific to the type of resin, but the first step is typically the automatic and/or manual sorting to ensure removal of contaminants and separation of different plastic streams. Technological progress, for example reliable detectors

\footnotetext{
${ }^{4}$ https://www.plasticseurope.org/en/focus-areas/circular-economy/zero-plasticslandfill/recycling-and-energy-recovery [24.11.2019].
} 
(such as FT-NIR) and sophisticated decision and recognition software, has helped to improve the productivity and accuracy of automatic sorting of plastics.

Although plastic recycling is a relatively mature process, there are still problems especially with regard to flexible packaging and composite materials. The challenges are mainly related to shortcomings in the collections, sorting and separation of different fractions of plastics with a high purity grade.

\section{Challenges with collection}

Waste collection is the transfer of solid wastes from the point-of use ('source') to disposal in terms of recycling, treatment or landfill. Waste collection includes the door-to-door and curbside collections and/or the transfer of waste to central collection points. Waste collection schemes vary considerably between European countries, but also between municipalities. Sometimes plastic waste is not collected separately but ends up in mixed municipal solid waste. In case of source-separation of plastic waste and plastic packaging in particular, there are different approaches: (1) mono-stream collection, where plastic waste is comingled with metals or multilayer packaging and (2) single or dual collection where plastic waste is collected as part of a dry recyclable streams with other types of recyclables such as paper and cardboard, glass or textiles. This takes place usually in terms of curbsidecollections, depot containers or recycling yards. However, there is the problem that many residents fail to separate the waste correctly. For instance, in Germany where packaging waste is collected separately in the "yellow bin", there is a misthrow-rate of about 40-60\% (BVSE 2019), which increases the cost of collection and processing and reduces the quality of recycled materials. Additionally, many things ending up in the waste bin are contaminated with grease, food, but also feces and other impurities making it very difficult to recycle.

\section{Challenges with separation}

Also the subsequent classification and sorting, aiming at separation of different waste streams is confronted with several challenges. In principle, the following requirements are placed on sorting processes: they should obtain marketable fractions of suitable quality, they should guarantee for high yields and sufficient 


\section{TOWARDS A SUSTAINABLE CIRCULAR ECONOMY}

throughput capacities at low running costs and low maintenance requirements. However, the sorting of plastics is challenging for multi-layer flexible packaging, composite materials and black-colored plastics. Black plastics account for a considerable proportion of the total volume of PE/PP in the plastic waste streams. However, carbon black and carbon absorb the radiation in the wavelength range of the near infrared detector and thus prevent detection. In addition, black objects can hardly be distinguished from the sorting belt. New innovative sorting methods are needed to detect and separate the black objects. There are promising approaches to this, e.g. the UniSort Black process from RTT/Steinert (Handschick 2019). Multilayer foils and films are rather complex compositions of hard foil, mostly made of PS/PE, soft films (PA/PE, PP/PA, PP/PA/PE), shrink films (PET/PE/EVOH/PE), laminated PET, PE or PP foils (aluminium, paper), metallized films (PET/Alu) or cellophane (Handschick 2019), which must be sorted or separated into usable fractions. Most multi-layer plastics are, however, usually be incinerated and landfilled due to their limited recyclability. There are options for the recycling of multi-layer packaging at the research state. In particular this is separation by mechanical, physical or chemical delaminations of layers and compatibilization by the addition of generation of suitable molecules that act as compatibilizers (Kaiser et al. 2018). All known approaches are able to recycle multilayer packaging, but are costly in terms of energy inputs (Kaiser et al. 2018).

\section{Plastic waste exports}

Although recycling technologies and energy-recovery are available, about half of the plastic collected is exported to countries outside the EU for "treatment". Previously a significant share of plastic waste was exported to China and Hong Kong. The quality of the recyclable materials declined gradually in terms of impurities. It turned out that much of the plastic waste was unmanageable waste. The Chinese government decided to implement the "green fence operation" aiming at improved quality monitoring of incoming waste flows and reduction of illegal shipping. In addition to China announced a new import policy in 2017, which is now limiting or banning the import of nonindustrial plastic waste. Several types of plastic waste from consumer goods, including PE, PS, PVC, PET, PP and bales of PET 
plastic bottles, aluminum plastic films, and compact disk/digital video disks are now banned (Brooks et al. 2018). Some types of plastics are conditionally accepted when meeting rather high quality requirements in terms of purity.

As a result the exports to China and Hong Kong have been decreasing, but exports are shifted to other countries in Asia (see Table 3).

Table 3. Overview on changes in imported plastic waste in different countries

\begin{tabular}{|c|c|c|c|c|c|c|c|c|c|c|}
\hline & $\begin{array}{l}\text { Chin } \\
\text { a }\end{array}$ & $\begin{array}{l}\text { Hong } \\
\text { Kong }\end{array}$ & India & $\begin{array}{l}\text { Indon } \\
\text { esia }\end{array}$ & $\begin{array}{l}\text { Mala } \\
\text { ysia }\end{array}$ & $\begin{array}{l}\text { Taiw } \\
\text { an }\end{array}$ & $\begin{array}{l}\text { Thail } \\
\text { and }\end{array}$ & $\begin{array}{l}\text { Turk } \\
\text { ey }\end{array}$ & $\begin{array}{l}\text { Vietn } \\
\text { am }\end{array}$ & $\begin{array}{l}\text { Other } \\
\mathrm{s}\end{array}$ \\
\hline & $\downarrow \downarrow$ & $\downarrow$ & $\uparrow$ & 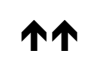 & 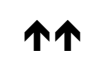 & 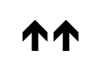 & 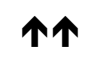 & 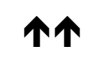 & 个个 & 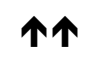 \\
\hline 2015 & $\begin{array}{c}1.658 \\
.971\end{array}$ & $\begin{array}{c}775.5 \\
58\end{array}$ & $\begin{array}{c}139.6 \\
28\end{array}$ & $\begin{array}{c}32.64 \\
0\end{array}$ & $\begin{array}{c}137.8 \\
77\end{array}$ & $\begin{array}{c}31.54 \\
8\end{array}$ & $\begin{array}{c}15.41 \\
4\end{array}$ & $\begin{array}{c}19.37 \\
8\end{array}$ & $\begin{array}{c}88.76 \\
1\end{array}$ & $\begin{array}{c}177.7 \\
42\end{array}$ \\
\hline 2018 & $\begin{array}{c}64.62 \\
2\end{array}$ & $\begin{array}{c}211.5 \\
30\end{array}$ & $\begin{array}{c}158.2 \\
51\end{array}$ & $\begin{array}{c}190.9 \\
33\end{array}$ & $\begin{array}{c}404.1 \\
24\end{array}$ & $\begin{array}{c}99.07 \\
1\end{array}$ & $\begin{array}{c}39.67 \\
6\end{array}$ & $\begin{array}{c}270.3 \\
40\end{array}$ & $\begin{array}{c}187.3 \\
78\end{array}$ & $\begin{array}{c}301.1 \\
36\end{array}$ \\
\hline
\end{tabular}

Source: EEA (2019)

\subsection{Wood waste and recycling - current state}

Wood waste represents an established recycling route. The collection and reverse logistics as well as the treatment and recycling technologies are rather mature in terms of technology readiness levels (Righeschi 2017). Hence, wood waste can be regarded as a good example of a functioning circular economy, although there remain minor and technically solvable problems. However, a larger contribution to sustainability could be made if woody biomass were used in cascades as a prerequisite for several of the advanced R9-Strategies described in Table 1.

\section{Sources and collection of wood waste}

Sources of wood waste are for instance industry, commerce, wood processing industry, demolition and construction waste, waste treatment facilities, trade as well 
as municipalities and private households. The following waste-wood categories can be distinguished (Righeschi 2017):

- Post consumer wood: household waste like furniture and commerce (package), construction waste, port related activities and wood-processing industry.

- Parks and gardens: wood scraps and leaves produced in private and public parks and gardens.

- Driftwood and rivers: wood coming from forests falling into rivers and then ending up on seaside because of sea currents and storms.

- Brushwood: wood and timber from local forest.

In order to allow for effective recycling, segregation at source or at an early stage is essential. Post consumer waste wood is collected in different ways, e.g. by regular kerb-site collection, door-to-door collections services as well as by recycling stations and private collection platforms. Parks and garden waste is usually collected by landscape maintenance companies, and then brought to local recycling stations. For citizens not able to bring their garden wastes to the recycling stations, door-todoor collection maybe available. Construction and demolition waste from building yards is disposed via pick-up or delivery to waste management companies. In the most waste management schemes, the waste producer needs to prove the legally correct disposal by means of a delivery certificate. The wood waste is typically unprocessed, coarsely pre-crushed or bulky. Wood waste coming to a storage or recycling facility needs to be weighed and allocated to a waste category. Then the material is unloaded to an inbound material storage by self-haulers. Again, qualified personnel is needed to check the delivery loads for mis-sorted waste and contaminants according to the waste wood categories (i.e. visual inspection). Contaminant materials, e.g. metal fittings, have no influence in the storage. Volumes, pile heights and the storage area size depend on local conditions and legal (statutory) requirements (e.g. OHS, air pollution, water pollution, fire protection. (VDI 4807) 


\section{Quality requirements and recycling options}

Recycled wood to be used for derived timber products must, according to the German regulation (i.e. Altholzverordnung AltholzV), meet limit values for several parameters for pollutant concentration (e.g. heavy metals, copper, chlorine, fluorine, pentachlorophenol, polychlorinated biphenyls). The use of wood chips for the production of wood composites is restricted to certain wood categories (i.e. untreated or mechanically treated wood, glued or painted wood without halogenorganic compounds or preservatives, wood containing halogen-organic compounds; without preservatives, wood containing halogen-organic compounds without preservatives, contaminated wood, including halogen-organic compounds, but without PCB.

In order to ensure environmentally treatment and recycling of waste wood, i.e. with minimal emissions of toxic substances and pollutants, the operator of a waste wood treatment plant must ensure that only the waste wood categories approved for this purpose are used. Additionally, all impurities must be removed (i.e. inorganic or organic substances foreign to wood, in particular soil material, stones, concrete, metal parts, paper, cardboard, textiles, plastics or foils that adhere to, are mixed with or are connected to the waste wood) and is free of PCB containing waste wood. Also for the energy recovery certain requirements have to be met. Energy recovery is limited to certain waste wood quality categories and firing plant sizes and thermal capacities.

\section{Pre-Treatment of wood waste}

Wood waste pre-treatment is required to meet the quality criteria for the subsequent materials recycling or energy recovery stage. Most important quality criteria are the particle size distribution (i.e. grading curve), contaminant fracture, pollutant concentration and moisture. Mobile and stationary processing technology can be used for the various unit processes (VDI 4087):

- Presorting aims at removal of contaminants that interfere with subsequent steps (i.e. solid metal items, stones, concretes, larger composites (carpet, mattresses), packaging materials, mis-sorted waste wood. Another objective of the presorting is to homogenize the batch. Presorting is carried out 
manually by hand or mechanically by means of excavators with sorting grabs. Presorted wood is then transferred to the next steps with excavators, wheel loaders or trucks.

- Particle size reduction ensures the required particle size, reduces and wood waste volume and helps to remove embedded contaminants). Primary size reduction allows, depending on the employed equipment (e.g. crushers, chippers, hammer mill, etc.), a reduction of particle sizes of 200 to $500 \mathrm{~mm}$. Ferrous scrap can be separated with magnetic separators, and manual sorting on a conveyor belt is employed to reduce other contaminants. Secondary size reductions aims at fine fractions for instance for wood chips $(<50$ to $200 \mathrm{~mm}$ ) and is accomplished with low- or high speed crushers or mills.

- Size classification is required to produce a specified particle size distribution or to meet other requirements regarding fine fractions and overlengths in order to prevent clogging in conveying belts. Various types of screening technologies are used (e.g. drum screens, star or disk screens, tumbler screens, oscillating screens, vibratory screens, bar sizers, etc.)

- Sorting refers to further removal of contaminants and segregation by waste wood categories. Sorting technologies include manual sorting (i.e. excavator sorting $(500 \mathrm{~mm}-50 \mathrm{~mm})$ and manual sorting $(>50 \mathrm{~mm})$ for coarse contaminants and mis-sorted materials. Automated sorting for metals is accomplished by magnetic separators (drum or overhead magnets) and eddy current separators and by gravity separators (air classification for lightweight plastics, paper, and sink-float processes for heavier items such as glass, stones, metals). For certain materials, also sensor basedtechnologies are employed (NIR for plastics and wood, X-ray for (dark) plastics and stones, and induction sorters for electrically conductive components).

\section{Recycling options for wood waste}

There are different routes for the recycling of wood waste apart of direct combustion and incineration, such as

1. processing waste wood into wood pellets 
2. manufacturing of wood-based panels

3. bioreffinery applications

Other recycling routes, for instance the production of syngas by Fischer-Tropsch Synthesis, gasification and pyrolysis and the manufacturing of activated carbon/industrial charcoal, are available but not further considered in this paper.

\section{Ad 1) Wood pellets}

Essentially the production of pellets is a process of densification (Krizan 2015). Pellets production usually includes the pre-treatment (if not done in another recycling facility as described above), the pelletization and the post-treatment of produced pellets (Döring 2011; Protic et al. 2011). The pre-treatment of wood waste is, as described above, related to reducing the particle size and removal of contaminants. Size reduction takes with chippers for coarse grinding and hammer mills for fine grinding. The smaller the particle size, the stronger the pellets will be (Protic et al. 2011). Another depending factor for pellet production is the moisture content and therefore dryers are employed for adjusting the moisture to specified levels. Force dryers seem to be the only reliable way to achieve an moisture optimum. Several types of dryers are on the market (e.g. tube bundle dryers, drum dryers, belt dryers, low temperature dryers, superheated steam dryers and fluidized bed dryers), with drum dryers being the state-of-the art (Protic et al. 2011). Drum dryers use heated air from heat exchangers (indirect drum dryers) or flue gases from furnaces for the drying process. Cyclones at the end of the drying section are used for separation from the hot gaseous stream. The dried material is then conveyed to silos for moisture equalization for 10-24 hours. Before being processed, particle sizes need to be balanced, i.e. separation of undesired fractions, in oscillating screens. The next step is conditioning, where a thin film of water is added on the surface of the wood particles to allow binding in the pelleting machines. The technology for wood pelleting has emerged from other fields where densification of material is necessary, for instance animal feed. Different milling machines are available, but ring die pellet mils seem to be common (Protic et al. 2011). Main elements are the dies and rollers. Incoming material is 'trapped' between the roller and die and is pressed through the die channels. In order to get pellets of appropriate 
quality, the space between die and rollers needs to be even. Pellets leave the mill as string and are cut with special knives into pieces of about $40 \mathrm{~mm}$. The temperature of the pellets after milling is between $80-130^{\circ} \mathrm{C}$ and therefore it needs cooling before further handling. The pellets are transported from the pelleting machine with a bucket elevator to the cooling machine. Common coolers use dry and cool air to remove heat and moisture from the pellets. The produced pellets are stored in silos and packed in smaller bags (10-25 kg) or jumbo bags (1-1,5 m3).

\section{Ad 2) Wood based panels ${ }^{5}$}

Wood-based panels include (VDI 3462/2):

- plywood - veneer panels, coreboard, moulded veneer products

- particleboards - structural particleboard, furniture-grade particleboard, OSB, moulded wood particle products

- fibreboard - wood fibre insulation board, LDF, MDF and HDF boards

- moulded wood fibre products

Plywood is made of several layers of wood veneers of other material layser (laminae, battens, particleboard) that are bonded together under pressure $(0,5-10$ $\mathrm{N} / \mathrm{mm} 2$ ) at temperatures between 100 and $150^{\circ} \mathrm{C}$. Different resin binder systems are used in the glueing process (urea formaldehyde resin UF, urea melamine formaldehyde resin MUF, phenol formaldehyde resin PF, white glue PVAc).

Particleboard and moulded particleboard products are made from dried wood particles, i.e. industrial wood waste, roundwood and specific types of recovered waste wood or straw. A first step, roundwood, recovered or green wood is broken down into chips and flakes. Recovered wood usually requires additional cleaning, i.e. removal metals or other heavy particles. In a particle drier, the particles are dried from their initial moisture content (i.e. 20 - $180 \%$ rel. to dry wood mass) to a final moisture content between 1 to $10 \%$ rel. to dry wood mass depending on the binders used. Different drying technologies are available, e.g. direct- and indirect heated particle driers, conveyor driers, recirculating air driers, rotary driers). For the gluing

\footnotetext{
${ }^{5}$ The following technical descriptions are based on the VDI guidline VDI 3462 on Emission control - Wood Machining and Processing, Machining and Finishing of Wood and WoodBased Materials.
} 
of the dried wood particles mechanical blenders are used. For the adhesive solution, that glues the particles together, different binders (primarily UF, but also MUF, MUPF, PF and PMDI or mixtures) and additives such as hydrophobing agents (e.g. paraffin's) or hardeners (e.g. aqueous solutions of ammonium sulphate) are mixed with water. The resonated particles are then air-laid, prepressed and forwarded to a multi-daylight, continous or calendar presses. The mat is pressed under heat (160$250^{\circ} \mathrm{C}$ ) and pressure (3-5 N/mm2). Particle mat is composed of a coarse core layer and two fine face layers. Finishing includes sanding and edge trimming as well as trimming to the final dimensions.

Fibreboards, such Low-density fibreboards (LDF), medium-density fibreboards (MDF) or high-density fibreboards (HDF) are made of wood fibres produced by thermo-mechanical pulping of wood chips. The wood-chips are washed and preheated in a vessel with steam at atmospheric pressure. Steamed wood chips are then dehydrated and fed into a digester with a plug-screw feeder. The digester is used to soften the wood chips with steam at 7 to 10 bar, which allows naturally occurring binders in the wood to work. The mixture of liberated wood-fibres and condensates are transported via a refiner/defibrator to a drier, where the mixture is flashed to atmospheric pressure. Volatile wood compounds are emitted with vapour and exhaust gases from the drier. Gluing of the fibres is the next step and accomplished with blowline blending, this means that the binder and adhesives are injected into the wood-fibre mixture via spray nozzles. In addition mechanical and pneumatic blending is applied to reduce adhesive solution and formaldehyde consumption. After the blending drum the fibres are conveyed to a cyclone, separated from the conveying air stream and discharged onto a fiber belt. The resonated fibres are then transferred in a classifier and sent via another cyclone and a mat former to the press. Mat former means that the resonated particles are air-laid into a continuous mat that is prepressed and the conveyed to single, batch or continuous or calender presses. The mat is pressed under heat (about $160-250^{\circ} \mathrm{C}$ ) and pressure (about 3-5 N/mm2) to form the particle board. Usually the particle mat has one coarse layer and two finer layers. Exhaust airs are captured and cleaned or used as combustion air in a firing system. The finishing stage includes a treatment of 
the surface, i.e. by sanding to remove the press skin and sawing and edge-trimming to adjust the thickness of the board.

Moulded wood fibre products are produced usually in dry processes. Similar to the production of fibreboards, the dried wood fibres are mixed with powedered binders and additives and, in some cases polyester is injected. The mixtures are airlaid into mats by forming machinges and pressed with roller presses (VDI 3462/2). Subsequently, the fibre mats are cut and pressed into moulded products in heated steel tools. Finally the moulded wood fibre is cut to the final dimension and laminated with plastic films or textile fabrics.

Wood-plastic composites (WPC) are made of wood fiber/flour and thermoplastics (i.e. PE, PP, PVC, PLA, in some cases even plastic recyclates) and other lingo-cellulosic or inorganic filler materials and additives (i.e. colorants, colorants, coupling agents, UV stabilizers, blowing agents, foaming agents, and lubricants). The compounding requires higher temperatures $\left(\max 200^{\circ} \mathrm{C}\right)$ to enhance the bonding of plastics and wood fibres (Taifor 2017). To get the material in the desired shape, extruders and injection moulding is used. Extruded WPS can be formed in solid and hollow profiles. There is a large variety of injection moulded parts, for instance mobile phone covers of car door panels and car interior (Kim, Pal 2011).

\section{Ad 3) Bioreffinery}

Biorefineries are combining process technologies between biogenic raw materials and industrial intermediates and final products (Kamm, Kamm 2007). In analogy to oil refineries, biorefineries are concerned with using biomass as efficiently and sustainably as possible. The objective is to utilize biomass building blocks as most complete as possible. Various types and concepts of bioreffineries are currently under development or in operation ${ }^{6}$ (Lindorfer et al. 2019), but the lignocellulose biorefinery (cellulose/hemicellulose/lignin biorefinery) is of particular importance to wood-waste. They are considered to have a huge potential for large scale application (Kamm, Kamm 2004), as the waste wood and other wood-like

\footnotetext{
${ }^{6}$ I.e. sugar or starch biorefinery, vegetable oil and algal lipid biorefinery, synthesis gas biorefinery, biogas biorefinery, green biorefinery.
} 
biomass is available in sufficient quantities and with sufficient quality. At the same time, market niches exist for the conversion products both in the conventional fossilbased chemical industry but as well in a future bio-based economy. Lignocellulosic materials consists of three primary chemical fractions that can be exploited as precursors for chemical processes:

- hemicelluloses/polyoses (a suger-polymer of pentosis)

- cellulose (which is a glucose polymer)

- lignin (a polymer of phenols).

Following a mechanical pre-treatment (i.e. reduction and grinding), the primary refining includes a physical-chemical pulping of the lignocelluloses. This means that, simply, pressure and temperature is applied to fractionize the biomass mixture into cellulose, hemicelluloses and lignin. Pulping can be accomplished with or without chemical agents (VDI 6310). A huge variety of solvents and combinations thereof have been used for the separation of wood components (so called "organosolv pulping"). Solvents can include acids or alkaline substances or ethanol. Organosolv processes (e.g. the Allcel process, see Areste et al. 2015; Pye et al. 1991; Lange et al. 2015) are considered as having advantages, especially as sources for lignin, because lignin can be easily separated from the pulping solvents.

The raw products, cellulose, hemicelluloses and lignin, can be processed in the secondary refining, where two approaches can be differentiated (though combinations are possible):

- Direct production of fermentable carbohydrates for further biotechnological conversion: The enzymatic conversion of cellulose and hemicellulose into monomer carbohydrates (sugars e.g. glucose, xylose, arabinose, etc.) takes place in the presence of pulped lignin, which can then be separated. The resulting carbohydrates can be further used in biotechnological production.

- Isolated processing of separate streams of cellulose, hemicelluloses and lignin: Cellulose can processed into paper or dissolving pulp or can be used as raw fermentation process following enzymatic hydrolysis. Several mono- and polymer carbohydrates from the hemicellulose fraction can as well be separated and finished (e.g. xylose). Other 
fermentable carbohydrates can be utilized as raw fermentation materials in other biotechnological processes. However, the separated hemicelluloses fraction may also contains a range of different chemicals (such as acetic acid, furfural) which may lead to a degradation of original hemicelluloses and need therefore be extracted. The extracted materials can be processed in the chemical sector.

- Lignin is produced in both approaches and can be used in various ways for valorizing. Lignin can be used directly as input material (e.g. lignosulphonates), as working material (i.e. injection-mouldable compounds), lignite-based composite materials (i.e. bioplastics, biopolymers), as component in binders and coatings or as surfactant and dispersant additive. Up to know it seems that the use of lignin for highvalue-added application seems largely unexploited (Lange et al. 2015). The valorization of lignite to chemicals may involves several options for new products. The major problem with the valorization of lignin is its structural diversity and heterogeneity. The single batches are not reproducible and differ much in their characteristics. This makes it hard to use it for up-scaled mass production and to add value in a larger scope. However, research on fractionation and purification processes aiming at reproducible lignite streams is ongoing (Lange et al. 2015).

\section{Cascading use}

Resource cascading aims at a sequential re-use of resources (such as wood, plastics, paper, textiles) for a multiple application as high-quality products before the final use for energy recovery (Sirkin, ten Houten 1994; Gustavsson, Sathre 2011; Höglmeier et al. 2017). Multi-stage cascade use of biomass takes place when a biogenic raw material is processed into a biobased end product and this end product is used at least once more. Only after multiple material uses an energetic use can follow. This is corresponds very much to the idea of a circular economy. In the wood sector, as well as in paper/cardboard, significant cascading material flows can be found. A typical cascade for wood ideally compromises the following product life's: (1) round timber production, (2) solid wood and veneer products (furniture), 
(3) chip-based products (particle boards), (4) fiber-based products (paper and cardboard). The final material use of wood waste is related to the (5) production of bio-based chemicals before the remaining end-of life products can be used for energy recovery. An ideal cascade like this would allow using wood in four different types of products over time before the waste wood is utilized for energy recovery.

In 2010, a cascade factor of 1.57 was calculated for both industries in Europe. This means that wood resources used from the forest were used slightly more than one and a half times (Mantau 2013). In recent years wood waste have been increasingly used to produce particle boards (Schrägle 2015 in Fehrenbach 2016). By means of an optimized sorting and treatment of wood, the complete amount of waste wood (in categories A I and AII) could potentially be returned to the market for material recycling. This is about 50-80\% of the German market volume in 2015 (Fehrenbach et al. 2016; Garcia, Hora 2017) and would allow to meet up to 50\% the fibre demand for derived timber products from recovered wood. However, only a smaller fraction of about 13 to $20 \%$ of waste wood is used for material recycling (Mantau 2013; Sommerhuber et al. 2015; Garcia, Hora 2017), and an even smaller fraction of approximately $6 \%$ in multiple-stage cascades (Höglmeier 2015). Another reason for the rather low material recycling is the fact that until recently, it was financially more attractive to sell waste wood (AI and A II) for energy recovery. Generally speaking, for an assessment of the environmental benefits of wood cascading, it should be kept in mind that whenever waste wood is used for material recycling it cannot be used to substitute fossil energy carriers such as coal (Höglmeier 2015).

\section{Challenges}

With the exception of paper and wood-based materials, a broad implementation of biomass cascades has not yet taken place, at least not in Germany. A differentiated analysis of barriers has shown that no single factors are responsible for this (see Table 4). 


\section{Table 4. Barriers towards enhanced recycling and circularity of waste-wood}

\begin{tabular}{|c|c|}
\hline Economical & $\begin{array}{l}\text { - Uncertainties in the supply of raw materials } \\
\text { - } \quad \text { High and fluctuating prices for biogenic raw materials } \\
\text { - } \quad \text { Lack of cooperation between the actors in the value chain } \\
\text { - } \quad \text { Lack of access to residual and waste materials (competition } \\
\text { with energy recovery) }\end{array}$ \\
\hline Market related & $\begin{array}{l}\text { - No unique selling point compared to conventionally } \\
\text { manufactured products } \\
\text { - Negative product image combined with recycled and } \\
\text { recycled materials } \\
\text { - General environmental concerns of end users }\end{array}$ \\
\hline $\begin{array}{l}\text { Political framework } \\
\text { an legislation }\end{array}$ & $\begin{array}{l}\text { - Subsidies for competing biomass uses (e.g. through } \\
\text { Renewable Energies Directive) } \\
\text { - Restrictions on waste and recycling management (e.g. } \\
\text { through the Waste Framework Directive) }\end{array}$ \\
\hline Technical issues & $\begin{array}{l}\text { - } \text { Inadequate technical properties / low product quality } \\
\text { - } \quad \text { Contamination by the use of waste material }\end{array}$ \\
\hline
\end{tabular}

Source: Fehrenbach et al. (2016).

Rather it is an interaction of various barriers that prevent an increased the use of biomass. These include the political framework conditions, i.e. the legal regulations, as well as market-specific barriers. It seems that the regulation does not exhibit a uniform strategy for the use of biomass and waste wood in particular. Every ton of biomass that is used to generate energy reduces the potential to use resources more efficiently in material cycles (Fehrenbach et al. 2016). For example, the energetic use of biomass was for a long time promoted by the by the Renewable Energy Sources Act (EEG) in Germany. However, since 2012 it is not possible anymore to apply for subsidies under the EEG for waste-wood-to energy regardless if existing or new installations are concerned. Hence, the economical feasibility depends on market prices. In 2017 the market sale price for waste wood (cat. A I) ranged between 70 and 80 EUR per ton for energy recovery, while sale prices for particleboard was indicated with approx. 60 EUR per ton (Garcia, Hora 2017). At least in the year 2015 and 2016, there has been an oversupply of waste wood in the market, which causes price drops and disposal bottlenecks (Fehrenbach 2016). This 
would, according to economic logic, create incentives for material recycling, as cheap input material is available. Strategy papers contain numerous declarations of intent to strengthen the cascade of biomass. However, practical implementation lacks a clear line, stability and ambitious goals (Fehrenbach et al. 2016). The Circular Economy package for instance refers directly to waste-wood only with regard to packaging waste. The proposed target for reuse and recycling is set $60 \%$ for 2025 and $75 \%$ for 2030 . Though, material recycling and energy recovery are considered as equivalent. For a long-term establishment of biomass cascades, their economic feasibility is crucial. Provided the right policy instruments are in place, reducing conflicting incentives between energy recovery and material recycling, there is room for optimism. Still, it is necessary to see the full picture here, taking into account an entire economic system which is - or should - move into the direction of a circular and bio-based economy. At least, the coupling of different industrial sectors should be aimed for, as in the case of PET recycling to textiles.

Distortions between petrochemical and bio-based products are just as undesirable as a competition between energetic and material use. Indirect distortions are related, for instance, to sustainability criteria for biomass production, which not always are required for petrochemical products. A factor of success for a circular economy in the field of wood and bio-waste is therefore to ensure equal political treatment of the material and energetic use of biomass (Fehrenbach et al. 2016; Odegard, Bergsma 2012).

However, it is not always a matter of political market interventions, as in the long run, only concepts that are not endlessly depended on state-aid have lasting success. Support of R\&D and start-up financing is desirable as a basis for industrial implementation, in particular to bridge the gap between product development at laboratory scale and up-scale to industry levels. Beyond that "seed fundings", market intervention may leads to further market distortions, i.e. complete or partial lock-out of certain innovative products or even the destruction of established cascades.

Another obstacle is a perceived lack of cooperation within the value chain. Involved companies involved often do not consider themselves as being a part of cascade. Thus, they only show interest if there is an interest in the recycling of the of 
by-products and waste products as alternative and cost-effective raw materials (Fehrenbach et al. 2016). Improved cooperation can be achieved, e.g. by taking into account recovery and recyclability of raw materials in product design (i.e. Design for Environment). The benefits of the circular economy are obvious (Goverse 2011): The use of cascades in the process is much easier, safer and more cost effective than the use of other materials (e.g. waste wood, printing inks in paper recycling). At the same time established structures and transparency over the process chain help to further implement cascade utilization (Fehrenbach et al. 2016).

Regarding technological barriers: A basic prerequisite for the establishment of cascades are functioning logistics and supply chains. Barriers are mainly seen concerning collections and sorting and hence the quality of waste-wood to be recovered (Fehrenbach et al. 2016). It is detrimental, when in the construction and demolition sector, waste wood of different qualities is disposed in one stream, i.e. not separated. As a result, untreated or only mechanically treated wood is mixed with contaminated or polluted with harmful substances. This problem occurs also in other sectors such as the commercial and private collection. Waste sorting in separation usually takes place at the recycling center, usually, by means of visual inspection, i.e. basis of quality features that can be directly seen. However, the quality requirements in terms of thresholds (e.g. arsenic, lead, etc.) are rather strict and would need laboratory analysis. Hence, it can be assumed that in order to avoid a misjudgement, a lot of woods is categorized in lower quality grades (i.e. category AIII or A IV). In Austria, for instance particular emphasis is given to source sorting (i.e. sorting directly at the source) and separate storage. Material passes are issued to the waste, indicating the type of waste, origin, treatment steps, contaminations and similar properties. For this purpose, the waste wood stream is first sorted and sampled (Fehrenbach et al. 2016).

\section{Conclusions}

This paper has provided an overview on the recent state and challenges of the circular economy by means of two example material (waste) streams of plastics and 
wood-waste. It is argued that the circular economy refers to the consistency strategy of sustainability and, being a technology driven approach, allows continuing with consumption and production patterns in a capitalistic and market based economy. The circular economy deals with closed-loop production and consumption systems, eliminating negative externalities and the reliance of import of natural resources, while reducing the ecological footprint. It aims at retreating from one-time use goods to "long-term prescription in a product-as-a-service way" which requires innovation in use cases and business models. From the two in-depth case studies on plastics and wood-waste in can be concluded, that there are a couple of advanced approaches. Recycling of plastics, for instance, is mature for a variety of plastics such as PET, PP and PE, but there are problems especially in the packaging sector. Here we see a very short product-lifetime of packaging materials and often a complex composition of materials (i.e. multilayer foils). The wood-sector shows that for wood of good quality, i.e. wood without pollutants from preservatives and paints, the circle is already closed. In order to improve the circularity factor, more cascades in the product use are recommended. Wood should be used in different products such as round timber, furniture, particle board and then it can be recycled for particle boards. At the end of this third product life, utilization in bio-refineries is technologically unproblematic. Incineration and energy recovery may represent the final stage of a sustainable and circular wood cascade. In order to upgrade the mature recycling processes towards increased circularity (see Table 1), a number of interventions have to take place to overcome recent barriers. But a solution to our sustainability problems must come from within the dominating (economic) system or at least be capable of being linked to it. My personal opinion is that a paradigm shift towards a less materialistic lifestyle is taking place in niches of society, but so far and foreseeably no critical mass has been reached. "It's your economy, stupid!" (Lotter 2019), and its large-scale transformation "on the fly" is unlikely to take place in the face of diverse institutional and technological path dependencies. The transition to a more sustainable and circular economy also include the way in which the interplay of technologies and sectors is organized and managed (Geels, Schot 2007; Grin et al. 2010). It can be assumed that, in addition to technologies, production and consumption patterns, purchasing preferences and values must also 
be changed as overarching forms of action coordination (Rip, Kemp 1998). The fundamental change from one regime state to another encompasses several subsystems of society and must be expected to take place over longer periods of time. Transition means that a reasonably stable socio-technical system ("dynamic equilibrium") reorganizes itself into a new stable system state. Such a transition is characterized by the following characteristics (Frantzeskaki et al. 2012)

- Transformations are co-evolutionary processes that demand multiple changes in socio-technical configurations

- Different actors from different social subsystems and social groups are involved ("multi-actor-process")

- Transformations are associated with - in terms of scope - radical changes that take place over longer periods of 25 to 50 years.

- Transformations include innovation (e.g. novel design for circularity approaches, reverse logistics and data-driven supply chain management as well recycling technologies) and ex-novation (e.g. linear take-make-waste models).

From an analytical perspective, there are, beside others, two approaches applied for theorizing about complex transitions of large-scale socio-technological systems: namely (a) the multi-impulse model for sustainability innovations and (b) the multilevel concept. Both approaches have in common that they consider social factors and actor constellations as central elements of a successful diffusion of sustainability innovations. In contrast to older models of the innovation research, i.e. technology push and market pull, various aspects and factors have to be taken into account to explain the diffusion of innovations (multi-impulse model, Fichter 2005). Still, there are push and pull factors. Push factors exert a pressure for change by provide alternatives or by delegitimization of existing structures ("throw away soviecy"). Such push factors can be technological innovations ("tech push") but also (supra-) governmental regulations and laws ("regulatory push", for instance ambitious recycling quota). Also civil society actors, consumer and environmental protection organisations or environmental movements such as "Fridays for Future" or the Ellen McArthur Foundation are of increasing importance as they are able to bring issues on the political agenda or by scandalizing ("civil society push"). Pull factors support 
alternative options and have a particular impact in early-stage innovations. Pull factors includes changing demand-side changes ("market pull"). The regulatory pull comprises state incentives in the form of direct or indirect subsidies and/or R\&D funding. Finally there is a vision pull, providing orientation for innovation processes. Often the vision pull is related to visionary leaders, such as Ellen McArthur, who is taking this role in the public sphere. The second analytical approach refers to the multi-level-perspective (MLP). The basic idea here is that transition and innovation within socio-technical systems takes place on different levels (Geels, Schot 2007; Grin et al. 2010; Verbong, Loorbach 2010). They are the result of interactions between the micro-level (niches), the meso-level (regime) and the macro-level (socio-technical landscape):

- Macro-level: cross-cutting developments, megatrends, changes is framework conditions, changes of the natural environment, economic and demographic development

- Meso-level: Socio-technical regimes include the predominant practical rules and technologies that are relevant to the predominant socio-technical systems stability and reinforcement. Socio-technical regimes are highly institutionalised and can be changed only in the medium term and under sufficient pressure

- Niches are 'innovation incubators' for radical novelties. They are important are important, because they allow for learning processes, e.g. about technical specification, user preferences, public policies, symbolic meanings. Niches are protected areas, in a way that they are shielded from market factors and allow for early stage innovations. Once industrial maturity has been reached, these innovations must provide additional impetus in a protected market niche. Such niche management includes the phases of shielding, nurturing, and enabling ("empowerment"), through which a successive regime change can be achieved (Smith and Raven 2012)

The theoretical perspectives described above may not only provide opportunities for analytical purposes, but also for orientation and fostering of the circular economy in terms of policies and governance. Sufficiency is an approach that relies on a mind shift in a consumer society. Or, as Leo Tolstoy allegedly put it "If you see that some aspect of your society is bad, and you want to improve it, there is only one 
way to do so: you have to improve people". However, my personal opinion is that a change in technology might be more likely than a change in the state of mind of people. And, on the other hand, the tech fix in terms of circular economy may allow continuing with a capitalistic market economy, which causes less environmental damages.

\section{References}

Aresta M., Dibenedetto A., Dumeignil F. (2015), Biorefineries - an introduction, Walter de Gruyter, Berlin/Boston.

Brennan G., Tennant M., Blomsma F. (2015), Business and production solutions. Closing the loop, in: Sustainability. Key issues, Kopnina H., Shoreman-Ouimet E. (eds), EarthScan, Routledge, London, pp. 219-239.

Brookes L. (1990), The greenhouse effect. The fallacies in the energy efficient solution, "Energy Policy", vol. 18 no. 2, pp. 199-201.

Brooks A., Wang S., Jambeck J.R. (2018), The Chinese import ban and its impact on global plastic waste trade, "Science Advances", vol. 4 no. 6, https://advances.sciencemag.org/content/4/6/eaat0131 [23.12.2019].

Brüggemann A. (2018), How energy-efficient is Germany?, KfW Research No. 213, Frankfurt/M.

BVSE (2019), Recycling Nachrichten, https://www.bvse.de/recycling/recycling-nachrichten/4371-testkampagne-der-dualen-systeme-startete-in-euskirchen.html [23.08.2019].

D’Alisa G., Federico D., Kallis G. (eds.) (2015), Degrowth. A vocabulary for a new era (Book info page containing download samples), Routledge, London.

Döring S. (2011), Pellets als Energieträger. Technologie und Anwendung, Springer, Berlin Heidelberg.

Dyllick T., Muff K. (2016), Clarifying the meaning of sustainable business. Introducing a typology from business-as-usual to true business sustainability, "Organization \& Environment", vol. 29, no. 2, pp. 156-174.

EEA (2019), The plastic waste trade in the circular economy, https://www.eea.europa.eu/themes/waste/resource-efficiency/the-plastic-waste-trade-in [28.11.2019].

EMF (2013), Towards the circular economy, vol.1, Ellen MacArthur Foundation, Isle of Wight.

Fehrenbach H., Breitmayer E., Kay S., Bienge K. (2017), Biomassekaskaden. Mehr Ressourceneffizienz durch Kaskadennutzung von Biomasse - von der Theorie zur Praxis, UBA Texte 53/2017, https://www.umweltbundesamt.de/sites/default/files/medien/1410/publikationen/2017-0613_texte_53-2017_biokaskaden_abschlussbericht.pdf [23.12.2019]. 
Fichter K. (2005), Interpreneurship. Nachhaltigkeitsinnovationen in interaktiven Perspektiven eines vernetzenden Unternehmenertums, Metropolis-Verlag, Marburg.

Frantzeskaki N., Loorbach D., Meadowcroft J. (2012), Governing transitions to sustainability. Transition management as a governance approach towards pursuing sustainability, "International Journal of Sustainable Development", vol. 15 no. 1/2, pp. 19-36.

Fussler C. (1996), Driving eco-innovation. A breakthrough discipline for innovation and sustainability, Pitman Publishing, London.

Garcia C.A., Hora G. (2017), State-of-the-art of waste wood supply chain in Germany and selected European countries, "Waste Management", vol. 70, pp. 189-197.

Geels F.W., Schot J. (2007), Typology of sociotechnical transition pathways, "Res Policy", vol. 36 no. 3, pp. 399-417.

Geissdoerfer M., Savaget P., Bocken N., Hultink E.J. (2016), The circular economy. A new sustainability paradigm?, "Journal of Cleaner Production", vol. 143, pp. 757-768.

Geyer R., Jambeck J.R., Law K.L. (2017), Production, use, and fate of all plastics ever made, "Science Advances", vol. 3 no. 7, https://advances.sciencemag.org/content/3/7/e1700782 [23.12.2019].

Goverse T., Hekkert M-P., Groenewegen P., Worrell E., Smits R.E.H.M. (2001), Wood innovation in the residential construction sector; opportunities and constraints, "Resources, Conservation and Recycling”, vol. 34, pp. 53-74.

Grin J., Rotmans J., Schot J. (2010), Transitions to sustainable development. New directions in the study of long term transformative change, Routledge, London.

Gustavsson L., Sathre R. (2011), Energy and CO2 analysis of wood substitution in construction, "Climatic Change", vol. 105 no. 1/2, pp. 129-153.

Handschick. B. (2019), Kunststoff-Sortierung - Anforderungen und Möglichkeiten. RTT Steinert $\mathrm{GmbH}$, Presentation at the 28th. Seminar "Kunststoffrecycling in Sachsen”, Dresden.

Harborth H.J. (1991), Dauerhafte Entwicklung statt globaler Umweltzerstörung, Sigma, Berlin.

Höglmeier K., Weber-Blaschke G., Richter K. (2017), Potentials for cascading of recovered wood from building deconstruction. A case study for south-east Germany, "Resources, Conservation and Recycling", vol. 117, pp. 304-314.

Hoglmeier K., Steubing B., Weber-Blaschke G., Richter K. (2015), LCA-based optimization of wood utilization under special consideration of a cascading use of wood, "Journal of Environmental Management”, vol. 152C, pp. 158-170.

Huber J. (1995), Nachhaltige Entwicklung. Strategien für eine ökologische und soziale Erdpolitik, Sigma, Berlin.

IEA (2017), World energy balances 2017, International Energy Agency, Paris. 


\section{TOWARDS A SUSTAINABLE CIRCULAR ECONOMY}

Jambeck J.R., Geyer R., Wilcox C., Siegler T.R., Perryman M., Andrady A., Narayan R., Law K.L. (2015), Plastic waste inputs from land into the ocean, "Science", no. 347, pp. 768-771.

Jörissen J., Kopfmüller J., Brandl V., Pateau M. (1999), Ein integratives Konzept nachhaltiger Entwicklung, Wissenschaftliche Berichte FZKA 6393, Forschungszentrum Karlsruhe.

Kaiser K., Schmid M., Schlummer M. (2018), Recycling of polymer-based multilayer packaging. A review, "Recycling", vol. 3 no. 1.

Kamm B., Kamm M. (2004), Biorefinery - systems, „Chemical and Biochemical Engineering Quaterly", vol. 18 no. 1, pp. 1-6.

Kim J.K., Pal K. (2011), Recent advances in the processing of wood-plastic composites, Springer, Berlin - Heidelberg.

Kirchherr J., Reike D., Hekkert M. (2017), Conceptualizing the circular economy. An analysis of 114 definitions, "Resources, Conservation \& Recycling", vol. 127, pp. 221-232.

Krizan P. (2015), The densification process of wood waste, De Gruyter Open Ltd, Warsaw - Berlin.

Lange H., Bartzoka E.D., Crestini C. (2015), Lignin biorefinery. Structure, pretreatment and use, in: Biorefineries. An introduction, Aresta M., Dibenedetto A., Dumeignil F. (eds.), Walter de Gruyter, Berlin - Boston, pp. 257-283.

Leal Filho W., Saari U., Fedoruk M., Iital A., Moora H., Klöga M., Voronova V. (2019), An overview of the problems posed by plastic products and the role of extended producer responsibility in Europe, "Journal of Cleaner Production", vol. 214, pp. 550-558.

Lieder M., Rashid A. (2016), Towards circular economy implementation. A comprehensive review in context of manufacturing industry, "Journal of Cleaner Production", vol. 115, pp. 36-51.

Lindorfer J., Lettner M., Hesser F., Fazeni K., Rosenfeld D., Annevelink B., Mandl M. (2019), Technical, economic and environmental assessment of biorefinery concepts. Developing a practical approach for characterization, IEA Bioenergy Task 42: Biorefining in a Circular Economy, https://www.ieabioenergy.com/wp-content/uploads/2019/07/TEE_assessment_report_final_201907041.pdf [23.12.2019].

Lotter W. (2019), It's your economy, stupid! Die Grünen leben in der Ökonomie der Industriegesellschaft, "Kursbuch", no. 197.

Mantau U., Saal U., Prins K., Steierer F., Lindner M., Verkerk H., Eggers J., Leek N., Oldenburger J., Asikainen A., Anttila P. (2010), EUwood. Real potential for changes in growth and use of EU forests. Final report, Hamburg.

METI (2004), Handbook on resource recycling legislation and 3R initiatives, Japanese Ministry of Economy, Trade and Industry, Tokyo.

Müller-Christ G. (2009), Salutogenese und Nachhaltigkeit. Die Ressourcenperspektive als moderierendes Element zwischen Gesundheitsmanagement und Unternehmensführung, in: Leithäuser T., Meyerhuber S., Schottmayer M., Sozialpsychologisches Organisationsverstehen, VS Verlag für Sozialwissenschaften, GWV Fachverlage GmbH, Wiesbaden, pp. 139-162 
nova institute (2019), Bio-based building blocks and polymers. Global capacities, production and trends 2018-2023, https://europeanbiotechnology.com/fileadmin/Content/NewsAndStories/2019/Nova_exec.pdf [23.12.2019].

Odegard I., Bergsma G. (2012), Cascading of biomass, 13 solutions for a sustainable biobased economy. Report, CE Delft, Delft.

Paech N. (2012), Liberation from excess. The road to a post-growth economy, oekom verlag, Munich.

PlasticsEurope (2018), Plastic - the facts. An analysis of European plastics production, demand and waste data, PlasticsEurope - Association of Plastics Manufacturers. Brussels, https://www.plasticseurope.org/download_file/force/2367/521 [23.12.2019].

Potting J., Hekkert M.P., Worrell E., Hanemaaijer A. (2017), Circular economy. Measuring innovation in the product chain, PBL Netherlands Assessment Agency, https://www.pbl.nl/sites/default/files/downloads/pbl-2016-circular-economy-measuring-innovation-inproduct-chains-2544.pdf [23.12.2019].

Protic M., Dragan M., Stefanovic V. (2011), Wood pellets production technology, "Safety Engineering", vol. 1 no. 1, pp. 23-26.

Pye E.K., Lora J.H. (1991), The Alcell process, a proven alternative to kraft pulping, "Tappi Journal”, vol. 74 no. 83 , pp. 113-118.

Righeschi S. ( 2017), Baseline evaluation of current wood waste recycling. Deliverable within the FORCE- Cities Cooperating for Circular Economy Project. Co-funded by the Horizon 2020 Framework Programme of the European Union, http://www.ce-force.eu/ [23.12.2019].

Rip A., Kemp R. (1998), Technological change, in: Human choice and climate change. International assessment, Rayner St., Malone E.L. (eds.), Battelle Press, Columbus, OH, pp. 327-399.

Robertson G.L. (2009), Food packaging and shelf life, in: Food packaging and shelf life. A practical guide, Robertson G.L. (ed.), CRC Press, Boca Raton, FL, pp. 1-16.

Robertson G.L. (2016), Packaging and food and beverage shelf life, in: The stability and shelf life of food, Robertson G.L. (ed.), 2nd ed., Woodhead Publishing, Cambridge.

Saunders H. (1992), The Khazzom-Brookes postulate and neoclassical growth, "Energy Journal", vol. 13 no. 4 , pp. 131-148.

Schrägle R. (2015), Schadstoffe in Spanplatten. Status quo vor dem Hintergrund von Kaskadennutzung und Altholzeinsatz, "HolzZentralblatt", no. 3, 16 January 2015, pp. 56-57.

Schumacher E.F. (1973), Small is beautiful. Economics as if people mattered, Blond \& Briggs, London.

Sieben D. (2007), Die innere Dimension der Nachhaltigkeit, “Ökologisches Wirtschaften”, vol. 22 no. 1, pp. 23-24. 


\section{TOWARDS A SUSTAINABLE CIRCULAR ECONOMY}

Sirkin T., ten Houten M. (1994), The cascade chain. A theory and tool for achieving resource sustainability with application for product design, "Resources, Conservation and Recycling", vol. 10 no. 3, pp. 213-277.

Smith A., Raven R. (2012), What is protective space? Reconsidering niches in transitions to sustainability, "Research Policy", vol. 41 no. 6, pp. 1025-1036.

Sommerhuber P. (2016), Resource efficiency of wood-plastic composites. Identifying secondary material substitution potentials and an environmentally sound end-of-life treatment, dissertation at Faculty of Mathematics, Informatics and Natural Sciences, Department of Biology of Universität Hamburg [unpublished].

Sorrell S., Dimitropoulos J., Sommerville M. (2009), Empirical estimates of the direct rebound effect. A review, "Energy Policy", vol. 37 no. 4, pp. 1356-1371.

Su B., Heshmati A., Geng Y., Yu X. (2013), A review of the circular economy in China. Moving from rhetoric to implementation, "Journal of Cleaner Production", vol. 42, pp. 215-227.

Taifor A. (2017), A review of wood plastic composites effect on the environment, "Journal of Babylon University/Engineering Sciences", vol. 25, no. 2, pp. 360-367.

Ten Brink P., Schweitzer J.P., Watkins E., Janssens C., De Smet M., Leslie H., Galgani F. (2018), Circular economy measures to keep plastics and their value in the economy, avoid waste and reduce marine litter, Economics Discussion Papers, http://www.economicsejournal.org/economics/discussionpapers/2018-3 [25.06.2018].

Thrän D., Arendt D., Adwiraah H., Kaltschmitt M. (2016), Nebenprodukte, Rückstände und Abfälle, in: Energie aus Biomasse - Grundlagen, Techniken und Verfahren, Kaltschmitt M., Hartmann H., Hofbauer H. (eds.), 3rd ed., Springer, Berlin - Heidelberg.

VDI 3462/2 (2013), Emission control, wood machining and processing. Production of wood-based panels, Verein Deutscher Ingenieure, Beuth Verlag, Berlin.

VDI 4807 (2016), Planning, construction and managing of scrap wood yards, Verein Deutscher Ingenieure, Beuth Verlag, Berlin.

VDI 6310 (2016), Classification and quality criteria of biorefineries, Verein Deutscher Ingenieure, Beuth Verlag, Berlin.

Verbong G., Loorbach D. (2010), Governing the energy transition. Reality, illusion or necessity?, Routledge, Taylor and Francis Group, New York.

Zalasiewicz J., Waters C.N., Ivar do Sul J., Corcoran P.L., Barnosky A.D., Cearreta A, Edgeworth M., Galuszka A., Jeandel C., Leinfelder R., McNeill J.R., Steffen W., Summerhayes C., Wagreich M., Williams M., Wolfe A.P., Yonan Y. (2016), The geological cycle of plastics and their use as a stratigraphic indicator of the Anthropocene, "Anthropocene”, vol. 13, pp. 4-17. 